\title{
Transfusões linguísticas: o percurso plagiotrópico na transcriação das duas cenas finais de Fausto II, por Haroldo de Campos
}

\author{
Ana Carolina Costa*
}

\section{Vampirismo e transfusão linguística}

Ele crava sutilmente seu lápis na veia do texto e, interrompendo o fluxo sanguíneo de significâncias, suga nutrientes criativos para si, postos no sangue do outro. Mais do que isso, opera, extraindo excertos de tecido tegumentar, e vai compondo a matéria de seu próprio texto. Com seu olho clínico, sabe escolher a parte primordial, aquela capaz de fazer coro, junto ao seu próprio tecido, com as peles de outras épocas. O resultado é um corpo híbrido, seiva vermelha e pele de multiplicidades, um texto-tecido formado de fragmentações. As palavras de Haroldo de Campos reforçam esta noção, quando afirma a expressão "vivissecção implacável do original" e "que lhe revolve as entranhas" (CAMPOS, 2005, p.75) enfatizando o ato de tradução como operação do texto, e reafirmando o tradutor como dono de um olho arguto para escolher o excerto exato. O tradutor é vampiro e cirurgião ao mesmo tempo, talvez a imagem real daquele composto de médico e monstro, de Robert Louis Stevenson. A imagem do tradutor como vampiro é também colhida em Campos, quando, via Hugh Kenner, afirma: "tradução como transfusão. De sangue. Com um dente de ironia poderíamos falar em vampirização, pensando agora no nutrimento do tradutor" (CAMPOS, 2005, p. 208). ${ }^{1}$

A ação de transfundir sangue e pele de um organismo para outro, no caso da tradução criativa, deve ser observada no que ela tem de mão dupla, isso porque não se trata apenas de um beber numa fonte alheia, mas o ato de reler/traduzir um texto pertencente a uma tradição, abre possibilidades de renovadas leituras deste original, e uma posterior reorganização dentro da dinâmica da tradição. Tápia fala de "contaminação" no ato das misturas destes sangues:

\footnotetext{
Doutora em Teoria Literária e professora do Departamento Acadêmico de Estudos Linguísticos e Literários da Universidade Federal de Rondônia, Campus de Vilhena, RR, Brasil. E-mail: ana.costa@unir.br.

1 A noção de tradução como transfusão é mencionada, numa perspectiva bastante similar a Campos, por Guilherme de Almeida em Flores das flores do mal de Baudelaire, (Tápia, 2013, p. 216). Almeida, objetivando afastar-se da noção de tradução como fidelidade linear, ratificará a transfusão como "revivificação de um organismo pela infiltração de sangue alheio, mas de 'tipo' igual" (Almeida, 2014, p.98).
} 
Adotando-se alguma liberdade de uso de nova alusão à metáfora vampiresca, pensaríamos que, além da nutrição do tradutor, haverá de certo modo, a "contaminação" da fonte alimentadora pela ação de quem a vampiriza, o que corresponderia à ideia de mutabilidade do original pela atuação crítica de sua tradução (TÁPIA, 2013, p.217).

O sangue do original, ao entrar em contato com o da tradução, torna-se outro, um novo relido pelo olho do gesto tradutório. O corpo do texto traduzido passa a ser nutrido por uma troca de sangues que acabará por reler/reposicionar, na tradição, a fonte primordial: " uma associação de identidades que envolveria a incorporação da qualidade alheia, na qual a identidade receptora se modifica e modifica a que recebe" (TÁPIA, 2013, p. 219). Para Campos, o processo vai além, quando num impulso luciferino almeja usurpar o "trono" do texto original, e mais, pôrse como um original, como uma "transluciferação" que "intenta, no limite, a rasura da origem" (CAMPOS, 2005, p. 209). O gesto operatório de "dissecar", fragmentando pela leitura cuidadosa e minuciosa do texto original, produz um tecido textual construído pela leitura do tradutor. O tecido textual da transcriação está, assim, perpassado pelos escombros desta origem. No ensaio "Paul Valéry e a poética da tradução: as formulações radicais do célebre poeta francês a respeito do ato de traduzir", Campos levanta quatro pontos, a partir de excertos do texto de Valéry, nos quais vai sinalizando tópicos para a noção de tradução criativa, fazendo do poeta e crítico francês um dos pioneiros a contribuir com a teoria e prática da transcriação. Para nossa discussão, enfatizamos o ponto um: "a ideia da literatura como uma operação tradutora permanente - escrever é traduzir -, logo a relativização da categoria da originalidade em favor de uma intertextualidade generalizada" (Campos, 2013, p. 62).

O aspecto de "intertextualidade generalizada" convida-nos a pensar o ato de traduzir aliado ao termo biológico, adaptado por Campos, para o estudo do espaço da tradição: a plagiotropia. Parte do inventário vocabular da botânica, plagiotropia é quando o caule de uma planta apresenta um crescimento diferente, quando vai dispensando a verticalidade e adotando o desenho dos galhos; desviado da ortotropia, o caule cresce vergado para um lado (WendLING, 2003). Assim, o vegetal, em processo plagiotrópico, impõe ao seu corpo um desvio, rechaçando um desenvolvimento vertical. Campos menciona o termo, recuperando a etimologia de plagiotropia, para enfatizar o oblíquo, a não linearidade e a transversalidade implicados na notação grega de plágios (CAMPOS, 2005, p. 75). ${ }^{2}$ A transversalidade, mutatis mutandis, seria a plasticidade que se delineia no procedimento de ruína da origem, no sentido de fragmentação, quando o tradutor luciferino usurpa e reconstrói, ao

\footnotetext{
"A plagiotropia (do gr. plágios, oblíquo; que não é em linha reta; transversal; de lado), tal como a entendi no curso que ministrei na primavera de 1978 na Universidade de Yale sobre a evolução de formas na poesia brasileira, se resolve em tradução da tradição, num sentido não necessariamente retilíneo. Encerra uma tentativa de descrição semiótica do processo literário como produto do revezamento contínuo de interpretantes, de uma "semiose ilimitada" ou "infinita" (Peirce; Eco), que se desenrola no espaço cultural” (CAMPOS, 2005, p. 75).
} 
criar seu próprio monstro, o corpo integral do texto base, reposicionando o lugar desse texto na evolução de uma tradição, rearticulando as estruturas que a impulsionam: "a história é objeto de uma construção cujo o lugar não é o tempo homogêneo e vazio, mas o preenchido de 'tempo de agora"' (BENJAmin, 2012, p. 249).

Nessa esteira, o texto-corpo formado por conjunto de veias que transportariam material linguístico entre si, passaria, no processo tradutório, por um adensamento do fluxo de significâncias e, consequentemente, do processo de transfusões linguísticas. O olhar do tradutor-criador deve ser capaz de penetrar esse tecido, sinalizando as caves ou reentrâncias, aqueles possíveis pontos de transfusão, nos quais, o fluxo mais violento de sangue fulgura. Campos, salientando a similaridade posta num estudo da historiografia do "como", afirma:

O status deste "como" (conjunção adverbial comparativa) não é afiançado pela lógica-discursiva, mas pela analógica da similitude. E aqui entra de novo Aristóteles, pai da lógica ocidental, "rector" do Logos, e teórico da metáfora, ou seja, padrasto da Analógica, da - por assim dizer - não lógica do terceiro incluído, onde uma coisa pode deixar de ser igual a si mesma para incorporar o outro, a diferença, desde que postulada uma relação de similaridade, cabendo ao poeta (sendo mesmo sinal de seu gênio) perceber estas relações - essas afinidades "simpoéticas”, capazes de reconciliar, no amplexo da mesmidade assim relativizada, o estranhamento subversivo da outridade (CAMPOS, 2006, p.149).

Se tomarmos essa "mesmidade assim relativizada" como o texto base, aqui relativizada sua "originalidade" pelo processo de tradução criativa, ou através do contato com o "estranhamento subversivo da outridade", depreenderemos que as caves ou reentrâncias que ora citamos, sinalizadas pelo "gênio" do poeta, propulsoras dos fluxos de trocas textuais, são relacionadas pela "analógica da similitude", um motor indispensável às complexas redes plagiotrópicas desenhadas a partir de uma transcriação. Neste ponto, entendemos a aferição de Campos (2005), quando afirma sua ideia de literatura como "operação tradutora permanente" e "intertextualidade generalizada". O caractere marcante dos textos literários está na sua multiplicidade de sentidos, nos seus "vazios", na riqueza de leituras fundamentais para renovação e reposição desses ao longo da tradição. O gesto do tradutor-criador é compatível com a plenitude, quando, encontrando caves de possibilidades, ofertadas pelo material linguístico do texto base, executa as pontes intertextuais, praticando uma tradução criativa, e acima de tudo crítica. Desta maneira, revisa-se o lugar do texto traduzido na tradição, reposicionando relações e criando precursores. ${ }^{3}$

A plagiotropia, enquanto proposta de revisão da tradição a partir de diálogos textuais, segue a "analógica da similitude" ou a "intertextualidade generalizada",

3 Borges diz: "o fato é que cada escritor cria seus precursores. Seu trabalho modifica nossa concepção do passado, como há de modificar o futuro" (2000, p.8o). Ampliamos aqui a noção para a tarefa do tradutor crítico e criador. 
mas a grande contribuição do procedimento, tão rico para o pensar dialético da produção de Campos, está na etimologia de "plágios" como "oblíquo". Curiosamente, Machado de Assis já havia dado uma acepção criativa ao termo 'plágio', potencializando-o como procedimento válido à criação:

Evidencia-se, então, que para Machado, o "plágio", em sentido figurado, sempre foi uma prática dos escritores, que ao citarem outros "confrades de versos" acabam se considerando os inventores dos textos que escrevem, conforme uma das reflexões de um relojoeiro: "citar a propósito um texto alheio, equivale a tê-lo inventado" (CunHA, 2004, p.4).

Porém, ao dar enfoque à nota plástica da obliquidade, contraposta a uma noção lógico-discursiva, Campos contribui para o entendimento da evolução de formas na literatura brasileira, chamando atenção para os tropismos transversais que vão se formando. Plasticamente nega o traço linear da continuidade, para incorporar a "diferença, o divergente", ${ }^{4}$ o desvio, como fator caro e necessário ao desenvolvimento de formas:

É aqui que entra Haroldo de Campos. Antes e depois dele, temos tido mediadores de qualidade. A invenção não prescinde deles ou tampouco os relega ao ostracismo. Faltava-nos, contudo, o crítico inventivo, i.e., capaz de enfrentar e dialogar com a reflexão teórica ou até impulsioná-la. Essa falta talvez se deva à educação recebida pelo crítico brasileiro. A partir da crítica que foi entre nós praticada desde finais do século XIX, ele teve como paradigmas ou o modelo sociológico ou o modelo filológico [...] O crítico de invenção, ao contrário, é o homem de juízo, i.e., aquele cuja apreciação assenta em uma disposição conceitual ou propensamente conceitual, a que alude ou demonstra (LIMA, 2005, p.122-123).

Compreendemos a apreciação baseada numa "disposição conceitual" como a leitura transversal da tradição, com a consequente busca do inventivo, no entendimento de nossa evolução literária. Lima vai defender também que há um princípio convergente nas produções críticas, tradutórias e criativas haroldianas: o foco na "experimentação" ou no "romper o consolidado". O rompimento da lógica linear será impulsionado por uma noção de transversalidade, presente do mesmo modo na crítica que perpassa as traduções e poemas do paulista.

É relevante também mencionar que Campos aponta na tradução uma "pulsão dionisíaca", algo capaz de "dissolve [r] a diamantização apolínea do texto original, já pré-formado, numa nova festa sígnica: [pondo] a cristalografia em reebulição de lava" (CAMPOS, 2005, p.181). A diamantização, também levada ao plano da tradição, lança sobre o lugar das obras a dureza da não permeabilidade. Para Campos, a múltipla rede intertextual que se estabelece a partir da tradução criativa, acaba por

4 Campos, 2006, p.148. 
converter a plagiotropia no impulso para a reorganização de uma tradição, "festa sígnica" de aporte de possibilidades. Pondo o texto base em reebulição de lava, ao construir novas camadas de leituras sob seu corpo textual, eleva a linguagem a altas temperaturas, dissolvendo fronteiras para o redesenho do espaço da tradição.

\section{Da pedra a pá: Goethe-Campos-Cabral}

Um exemplo desta prática está na tradução das duas cenas finais de Fausto II, por Haroldo de Campos. A rede que se põe aqui nasce em Goethe que, voltado ao passado da literatura inglesa, torna-se 'precursor' de Shakespeare ao recuperar a diç̧ão dos coveiros hamletianos no introito da cena Grablegung (Fausto II). No ato de cavar a sepultura de Fausto, os lêmures cantam ironicamente o compartimento de terra, a cova, como uma casa magra e fria, assolada pela estreiteza, morada do corpo. Do lado da alma, também de forma irônica, relembram a aposta, metaforizando-a como "mobília emprestada", coisa já vendida, e agora cobrada: "chegam os credores, quem é que paga?" (CAMPos, 2005, p. 7). O introito da cena já doa o tom mesclado de drama satírico que seguirá ao longo da disputa dos anjos e demônios pela alma de Fausto. É importante mencionar que a riqueza de tom que por si só já demandaria estudo à parte - contém uma rede de referências paródicas que se arrasta muito longe no tempo, indo até o resgate de raízes bíblicas na Epistola de São fudas (MAZZARI, 2007, p. 989-990).

Efetuando, pois, pequena incisão, com um gesto cirúrgico, nosso objetivo é o recuo no tempo dos séculos XVII-XX, cotejando os excertos dos coveiros de Goethe (recriador de Shakespeare) com a tradução de Campos. A versão em português da peça segue uma tendência que está presente no texto original, retomando a linha da ramificação oblíqua, quando verte linguagem e aporte crítico-criativo, aproximando o texto a partes de Morte e vida severina. Seguindo a tendência de suas traduções, Campos comenta as escolhas e o caminho que perseguiu, em sua empresa tradutória, em "Transluciferação mefistofáustica". A transcriação da abertura da cena "Enterramento" foi inspirada no ritmo do poema de João Cabral de Melo Neto, reiterando sua proposta de tradução como crítica:

A tradução é também um persona através da qual fala a tradição. Nesse sentido, como a paródia, ela é também um "canto paralelo", um diálogo não apenas com a voz do original, mas com outras vozes textuais. Assim, ela se deixa derivar no movimento plagiotrópico geral da literatura, de que falei no ensaio inicial, e que tanto afina com a ideia que tinha Goethe da apropriação, pelo poeta, do patrimônio literário extante [...] Na recriação do "Coro do Lêmures" (Grablegung, Enterramento), usei deliberadamente de uma dicção cabralina, haurida no auto Vida e Morte Severina (CAMPOS, 2005, p. 190).

Mencionamos ainda que "Enterramento" reverbera as costuras que vão se fazendo ao longo de Fausto I e II, perpassado de excertos de outros textos da tradição, como: Petrarca, Dante, Bíblia, entre outros. 


\section{A concreção da poesia cabralina: a dicção da "pá"}

Uma poesia a golpes de pá, diríamos, ou melhor, de pedra. A dicção poética de Cabral está marcada por um profundo tratamento com a massa sígnica, o que faz dele um poeta singular. Para Campos, a poesia de Cabral é um fio que ecoa as transformações alcançadas pela semana de 1922, como um entroncamento criativo da "poesia-minuto de Oswald de Andrade [...] que passa a informar certos poemas do primeiro Drummond e vai encontrar o seu lugar natural na linguagem reduzida da poesia cabralina" e ainda informa no poeta "uma acentuada propensão pelo substantivo e pelo concreto" (CAMPOS, 2006, p. 78-79). A opção pelo percurso dificultoso é traço de uma poesia que busca o concreto através da escolha pontual das palavras, tendo sua beleza figurada pela "dureza da pedra" (GonçALves, 1989, p. 50). Segundo Campos, Cabral instaura na poesia brasileira uma vertente "de construção, racionalista e objetiva", do lado oposto da poesia praticada pela geração de 1945, praticante de uma "poesia de expressão, subjetiva irracionalista" (CAMPOS, 2006, p. 8o, grifo do autor). É talvez no ponto de noção construtiva que se justifica a escolha de Campos pela dicção de Cabral em sua tradução. Além da questão do ritmo, almejamos apontar uma maior presença da poética de Morte e vida severina nesta tradução, incluindo o trato com a morte, figurativizada por um tônus imagético e melódico (principalmente, numa preterição das rimas em oxítonas), além de outras questões atreladas à concreção.

\section{Cavando o canto dos Lêmures}

Em primeiro lugar, no tocante ao tecido melopaico, mencionamos que o ritmo do texto de Cabral é marcado especialmente pela redondilha maior, com algumas combinações com versos tetrassílabos e rimas toantes. Campos optou por uma combinação similar, utilizando ora duas redondilhas menores, ora eneassílabos divididos pela conjugação de versos de redondilha menor e versos tetrassilábicos. Campos escolheu ainda a mescla de rimas toantes, consoantes e rimas internas. Configurada como dois lados da mesma moeda, o tom da vida severina cozida nas malhas da penúria, escassez e sofrimento físico está presente também, na tradução de Campos, pela escolha de adjetivos como "mesquinho", "estreita", "fria", "magra", "dívida". Em "Enterramento", Campos transformará a pedra da concreção cabralina no que chamamos de "dicção da pá", isto é, uma poesia vincada pela organização da camada sintagmática, cavucando uma estrutura rítmica e melopaica, ao transubstanciar o movimento da ferramenta que cava reiteradamente a cova para o corpo de Fausto. Começamos, desta maneira, cotejando o "Coro dos Lêmures" com um excerto de Morte e vida severina:

\section{LÊMURE (solo):}

Quem fez esta casa, espaço mesquinho,

A golpes de pá e de escavadeira?

\section{LÊMURES (coro):}


Hóspede negro, vestido de linho,

Estás muito bem nesta casa estreita.

LÊMURE (solo):

Ninguém pôs a mesa na sala fria,

Nenhuma cadeira na sala magra.

LÊMURES (coro):

Mobília emprestada, venceu a dívida.

Chegam os credores, quem é que paga? ${ }^{5}$ (Goethe, 2005, p.192).

(Encontra dois homens carregando um defunto numa rede, aos gritos de: "Ó irmãos das almas! Irmãos das almas! Não fui eu que matei não!”)

- A quem estais carregando, irmão das almas,

embrulhado nesta rede?

dizei que eu saiba.

- A um defunto de nada,

irmão das almas,

que há muitas horas viaja

à sua morada (NeTO, 1994, p.30).

Ao traduzir Goethe, Campos recupera uma noção de poesia crua, condensada, enxuta, transformando a aridez da morte em linguagem. É notável a simbologia fúnebre oculta nas metáforas que percorrem ambos os textos. Já nos primeiros versos, a tradução traz o vocábulo casa, sugerindo o lugar da morada eterna, no sentido de cova (percebam a similaridade de sons em ambas). A casa é um "espaço mesquinho", medido a "golpes de pá e escavadeira". Aqui cabe notar que a escolha de Campos segue o verso original em alemão: "Wer hat das Haus so schlecht gebaut", com "das Haus", significando a casa. Segall, do mesmo modo, traduzirá o verso, valendo-se da metáfora da moradia: "quem tem tão mal construído a casa" (SEGALL, 2007, p. 993). Para efeito de cotejo, trazemos Shakespeare, texto no qual também estão presentes as imagens da casa, picareta e pá:

$1^{\circ}$ Coveiro [...] Deixa de quebrar a cabeça por causa disso [...] As casas que ele faz duram até o dia do Juízo Final. [...] (Canta): Com picareta e uma pá, uma pá, / Em torno uma branca mortalha: / Um punhado de cal cai na cova, / E um novo corpo se agasalha ${ }^{6}$ (SHAKESPEARE, 2017, p.311, grifo nosso).

É notável a semelhança de tom no primeiro verso da tradução de Campos: "Quem fez esta casa, espaço mesquinho", e "Assiste ao enterro de um trabalhador

\footnotetext{
5 Tradução de Campos.

6 Tradução de Bárbara Heliodora.
} 
de eito e ouve o que dizem do morto os amigos que o levaram ao cemitério", de Morte e vida severina, no verso: "Essa cova em que estás,/ com palmos medida". A linha paronomástica que liga os vocábulos, casa e cova, incita a construção de uma metáfora sonora: o som vocálico [a], combinado com [k], é seco, magro, num eco do mesquinho e estreito; já o /o/ recupera uma noção de redondeza e escuridão, como no desenho de um buraco profundo. Há ainda, no mesmo texto, uma menção ao ato da terra vestir o defunto, com a diferença de que apenas a terra cobrirá o corpo enterrado do "trabalhador de eito", enquanto o corpo de Fausto estará coberto por um tecido de linho: "Tua roupa melhor/ será de terra e não de fazenda:/não se rasga nem se remenda./Tua roupa melhor/ e te ficará bem cingida:/como roupa feita à medida"; e, na tradução de Goethe: "Hóspede negro, vestido de linho/ Estás muito bem nesta casa estreita".

Os versos, na tradução de Campos, são decassilábicos, com hemistíquios marcados sempre pela quinta sílaba poética - a golpes de pá, diríamos - dividindo-os em duas redondilhas menores. A exceção é o terceiro verso, no qual temos um hemistíquio que transforma o verso em tetrassílabo e redondilha menor. Campos explica que opta por esta combinação para que os hemistíquios ecoem a variedade métrica presente no excerto mais acima de Morte e vida severina, quando Cabral compõe o diálogo em redondilhas maiores e tetrassílabos:

No Enterramento, vali-me de um decassílabo que se deixa prosodicamente dividir em hemistíquios [...] pontuando essa escanção, para maior realce, com rimas internas, toantes (cAsA/pÁ; nEgro/bEm; $\mathrm{mEsa} / \mathrm{cadEira/;}$ no sexto verso, mobília rima com dÍvida, e emprestAdA com pAgA no sétimo); as rimas terminais são toantes (à exceção de mesquINHO/IInhO, consoante). O efeito de "toada", em que os hemistíquios de certo modo respondem um ao outro, como partes de um contraponto frásico, não deixa de evocar o modelo cabralino, que é também um canto fúnebre, em grande parte do andamento (CAMPOS, 2005, p.192).

O trato poético da morte, em Cabral e na tradução de Campos, é reiterado através desta melodia cadenciada construída pelas rimas toantes e consoantes, e métrica dos versos. Na transcriação de Goethe, a música fúnebre está mimetizada, por exemplo, na pancada audível da pá, que bate ao chão, principalmente nos dois primeiros versos, nas oclusivas surdas e sonoras: /Quem/, /esTa/, /Casa/, /esPaço/, /mesQuinho/, /GolPes/, /De/, /Pá/, /esCavaDeira/. Convém notar que o monossílabo tônico "pá", onomatopaicamente, mimetiza o som produzido pela ferramenta, o que reafirma ainda mais nossa reflexão.

Como chamamos atenção acima, a metáfora sonora nas palavras "casa" e "cova" que, em um trocadilho, chama ainda o vocábulo "cava", recupera todo o contexto da morte e da sepultura feita para receber os corpos, da ação que, assim como na construção de um lar, é executada para garantir o repouso eterno da matéria. Sobre isso, é interessante notar as nuances significantes que vão assumindo o substantivo cova, em "Assiste o enterro de um trabalhador", em Morte e vida severina. 
A cova é agora a conquista maior da vida do trabalhador, o atingir, na morte, de um objetivo que não foi possível em vida: "É de bom tamanho,/ nem largo nem fundo,/ é a parte que te cabe deste latifúndio [...] é a terra que querias/ ver dividida". A cova vai assumindo ironicamente o ar de espaço de aconchego, abrigo, da roça nunca obtida, do trabalho livre, da vestimenta, ela é meio e fim:

\author{
- Viverás, e para sempre \\ na terra que aqui aforas: \\ e terás enfim tua roça \\ - Aí ficarás para sempre, \\ livre do sol e da chuva, \\ criando tuas saúvas. \\ - Agora trabalharás \\ só para ti, não a meias, \\ como antes em terra alheia. \\ [...] \\ - Trabalhando nesta terra, \\ tu sozinho tudo empreitas: \\ serás semente, adubo, colheita \\ (Neto, 1994, p.42).
}

Todas estas conotações vão delineando a cova como a habitação, propriedade onde o homem se abriga e retira de lá seu alimento e vestimenta, a sepultura assume, deste modo, o lugar de casa. A ação de aprontar ou construir a sepultura está, pois, em ambos os textos, a "cova com palmos medida" é, na tradução de Campos, feita: "Quem fez esta casa [...] a golpes de pá e de escavadeira?". Aqui, quando opta pelo verbo fazer, numa aproximação ao tom mais popular do texto de Cabral, não se afasta do original, no qual a combinatória de hat gebaut, pode ser traduzido como o pretérito do verbo construir, sendo hat o auxiliar e gebaut o particípio: "Wer hat Haus so schlecht gebaut".

O tamanho, porém, da "casa" para receber os corpos confunde-se e denuncia as personalidades divergentes dos personagens: Fausto, um ambicioso homem que obteve glórias e prazeres do mundo é enterrado "vestido de linho", e a sepultura é curta para "amplidão" do espírito: "estás muito bem nesta casa estreita". Já "o trabalhador de eito" é o oposto da grandeza, portador de uma vida magra, pobre e sem nenhum privilégio, na qual só encontra descanso e justiça na morte. Seu corpo, fruto do sofrimento e da privação, é pouco para uma simples cova: "É uma cova grande/para teu defunto parco [...]/ É uma cova grande/ para tua carne pouca". Na tradução de Bárbara Heliodora, os coveiros de Shakespeare, no ato V cena I, vão insuflando o diálogo com Hamlet a partir de trocadilhos com a linguagem, lançando ironia à morte:

\footnotetext{
7 Segall traduzirá o verso da seguinte maneira: "Quem tem tão mal construído a casa” (2007, p.993).
} 
Hamlet: De quem é essa cova? / $1^{\circ}$ Coveiro: Minha, senhor (Canta)/ Um punhado de cal cai na cova / E um novo corpo de agasalha/ Hamlet: Creio que é tua, realmente, pois estás dentro dela. $1^{\circ}$ Coveiro: Estais fora dela, senhor, portanto, não é vossa. [...] Hamlet: Mentes ao dizeres que é tua porque estás nela; isto é para os mortos, não para os vivos. [...] $1^{\circ}$ Coveiro: Mentira viva, senhor, que vivamente passa de mim para vós. [...] Hamlet: Como é preciso esse sujeito. Temos de falar muito claro, ou nos perderemos em seus equívocos (SHAKESPEARE, 2017, p. 313, grifo do autor).

O coveiro, como senhor dos equívocos, lembra-nos a imagem do poeta, cavucando as fendas para o resgate de 'ossos' valiosos, e executando enterros, mesmo que sazonais, de estilos de escrita: "A Arte é longa e o Tempo é breve./ Longe dos túmulos famosos,/ Num cemitério já sepulto/ Muito ouro ali jaz sonolento/ Em meio à treva e ao esquecimento/ Esquivo à sonda e ao enxadão" (BAUDELAIRE, 2006, p. 141). Fica claro, pois, o apuro de Campos em recriar o texto de Fausto II, a partir do tom do excerto de Morte e vida severina, introjetando-o na pele dos versos de Goethe. É notória também a preocupação do tradutor brasileiro em reconstruir a rede plagiotrópica que orbita em torno das duas cenas finais, principalmente no tocante à continuação do teor criativo: a diç̧ão de Cabral é, pois, replicada em raios que vão percorrendo e tensionando a informação poética do texto.

Cabe ainda algumas colocações a respeito da escolha de Campos para o título da cena. O vocábulo "Grablegung" é traduzido por Campos em "Enterramento", diferente de Segall que opta literalmente por "Inumação". A escolha de Campos soa estranha, uma vez que o mais comum seria "enterro" ou mesmo "sepultamento". Contudo, o poeta-tradutor brasileiro, numa busca por recuperar no substantivo a ação do verbo "sepultar", escolhe "enterramento", a palavra, portanto, acaba por significar um processo contínuo, como num presente eterno, acionado toda vez que o texto for lido. É notável também o parco uso dos adjetivos, e, quando utilizados, postos a serviço da visualidade, como: "espaço mesquinho", "sala fria", "sala magra", "mobília emprestada".

No "Coro dos Lêmures", da cena "Enterramento", a dureza da pá percorre a dinâmica sonora posta na tradução, num uso reiterado da aliteração das oclusivas, criando uma conjunção melódica cadenciada, como, por exemplo: /Casa/, /esPaço/, /mesQuinho/, /GolPes/, /De/, /escavaDeira/, "hósPeDe", /vesTiDo/, /esTás/, /muiTo/,/esTreiTa/,/Pôs/,/CaDeira/,/emPresTaDa/, /DíviDa/,/CreDores/, /PaGa/. Esta dicção da pá é responsável por uma compreensão cíclica do trecho, já que a palavra "pá" ajuda a iniciar a cena e finalizá-la, quando é repetida na rima toante magra /PAga. O movimento da pá, que cava a sepultura do personagem principal da peça, vai percorrendo todos os versos do "Coro dos Lêmures", para depois ser trocado pela proliferação do discurso de Mefistófeles. Aliás, o exame comparado deste preâmbulo, se assim podemos chamar a entrada da cena "Enterramento", do tom dos Lêmures e do tom mefistofélico, confirmará nosso raciocínio da dicção cabralina da pá, e sua influência na tradução, pois é notável a mudança, quando o personagem diabólico entra em cena. Há uma passagem de um discurso mais con- 
ciso, cadenciado, tensionado pela conjunção dos decassílabos divididos em hemistíquios, para um texto de ritmo frenético, com abundância de palavras, trazendo uma diç̧ão carnavalizada:

\title{
Lêmures (coro)
}

Mobília emprestada, venceu a dívida.

Chegam os credores, quem é que paga?

\author{
Mefistófeles \\ Deitou-se o cadáver. A alma quer voar? \\ Mostro-lhe o pacto, em sangue subscrito. \\ Que lástima, se há meios de arrancar \\ Ao demônio - hoje em dia -um espírito ... \\ A gente resiste aos antigos métodos, \\ E eu não me sinto adaptado aos novos; \\ Preciso agora de um bando de adeptos \\ Para fazer o trabalho de um só ${ }^{8}$ (Goethe, 2005, p.9).
}

Campos focando a epígrafe do livro $O$ engenheiro (1945), na qual Cabral irá valer-se da expressão de autoria de Le Corbusier: "machine à emouvoir", diz: "ambos, poeta e arquiteto pertencem a mesma família espiritual - a dos construtores -, na qual se inserem as melhores admirações de JCMN" (CAMPOS, 2006, p. 80). A alusão chama a discussão algo que é fundamental ao processo de criação de Cabral, e do método de tradução crítico e criativo de Campos: a ideia do poema como construção. A voz de Goethe é transcriada, reescrita sob a caneta do poeta e crítico, pois ao mesmo tempo em que traduz, tendo em vista sua própria noção de poesia, repropõe o lugar dos autores na tradição, possibilitando um tropismo trino: Goethe/ Cabral/ Campos. Os versos de Goethe, embebidos na dicção de outras poéticas, funcionam conjuntamente como "máquina para emocionar". Para além dos caminhos passíveis de leituras plagiotrópicas, aqui apresentados na tradução executada por Haroldo de Campos, é mister afirmar as possibilidades que se nos apresentam a leitura no original das duas cenas finais de Fausto II. Correm, conjugadas ao texto de Goethe, referências bíblicas, menções à cultura medieval, como lendas e pinturas, além da presença de autores como o sueco Emanuel Swedenborg (Mazzari, 2007, p. 1033); Dante Aliguieri, entre outros. O fato é que o princípio de apropriação afirmado por Goethe percorre os dois tomos de Fausto, abrindo uma vertente de leitura por "ramificação oblíqua" deste clássico da literatura mundial. Campos, na sua busca intermitente para recriar a informação estética do texto original, não poderia deixar de fora o procedimento da reproposição dos lugares dos textos da tradição. Confirmando assim, sua proposta de tradução como crítica, soube recriar não somente a poiesis goethiana, mas também uma parte fundamental da elaboração desta, quando plagiotropicamente trouxe o dramaturgo alemão para dialogar com a alta poesia brasileira. Como na Cozinha da

\footnotetext{
8 Tradução de Campos.
} 
bruxa (Hexenküche), cena de Fausto I, o caldo amalgamado dos discursos críticopoéticos deu origem ao elixir do novo, revivescendo as dicções e reposicionando as cadeiras das obras na linha evolutiva da tradição.

\section{Referências}

AlmeidA, Guilherme de. Flores das Flores do mal de Baudelaire. Ilustrações Henri Matisse; apresentação de Manuel Bandeira; posfácio de Marcelo Tápia; edição bilíngue. São Paulo: Editora 34, 2014.

Baudelaire, Charles. As flores do mal. Tradução, introdução e notas de Ivan Junqueira. 1ed.especial. Rio de Janeiro: Nova Fronteira, 2006.

Benjamin, Walter. Magia e técnica, arte e política: ensaios sobre literatura e história da cultura. Tradução de Sérgio Paulo Rouanet. São Paulo: Brasiliense, 2012.

Borges, Jorge Luís. "Kafka e seus precursores" In: Obras Completas Vol. II: Outras Inquisições. Tradução de Sérgio Molina. SP: Globo, 20oo. p. 78-8o.

CAmpos, Haroldo de. Paul Valéry e a Poética da Tradução: as formulações radicais do célebre poeta francês a respeito do ato de traduzir. In: Transcriação. TÁpIA, M.; Nóbrega, T. M.(Org.). São Paulo: Perspectiva, 2013.

Campos, Haroldo de. Metalinguagem e outras metas. 4 ed. São Paulo: Perspectiva (Coleção Debates), 2006.

CAmpos, Haroldo de. Deus e o Diabo no Fausto de Goethe: marginalia fáustica (leitura do poema acompanhada da transcriação em português das duas cenas finais da Segunda Parte). São Paulo: Perspectiva, 2005.

CunHA, Eliane Fernanda. "Da citação como Tradução e crítica na obra de Machado de Assis”. Rev. do Instituto de Letras da UFRGS, Rio Grande do Sul, v. 18, n.37, 2004. Disponível em: https://seer.ufrgs.br/organon/article/view/31173. Acesso em $21 \mathrm{de}$ março 2020.

Goethe, Johann Wolfgang von. Fausto (Segunda Parte) Uma Tragédia. Tradução de Jenny Klabin Segall. Apresentação, comentário e notas de Marcus Vinicius Mazzari. Edição bilíngue. São Paulo: Editora 34, 2007.

Goethe, Johann Wolfgang von. Enterramento. In: CAmpos, H. Deus e o Diabo no Fausto de Goethe: marginalia fáustica (leitura do poema acompanhada da transcriação em português das duas cenas finais da Segunda Parte). São Paulo: Perspectiva, 2005 .

Gonçalves, A. Transição \& Permanência - Miró/ João Cabral: Da tela ao texto. São Paulo: Iluminuras, 1989.

Lima, L. C. "Haroldo, o multiplicador". In: Motta, L. T. (org). Céu- acima: Para um tombeau de Haroldo de Campos. São Paulo: Perspectiva, 2005. (col. Signos, v.45). 
Mazzari, M. V. Abertura à cena "Inumação". In: Goethe, J. W. Fausto (Segunda Parte) Uma Tragédia. Tradução de Jenny Klabin Segall. Apresentação, comentário e notas de Marcus Vinicius Mazzari. Edição bilíngue. São Paulo: Editora 34, 2007.

Neto, J. C. M. Morte e Vida Severina e outros poemas para vozes. 34 ed. Rio de Janeiro: Nova Fronteira, 1994.

Shakespeare, W. Grandes obras de Shakespeare: volume 1: Tragédias. Tradução de Bárbara Heliodora. Rio de Janeiro: Nova Fronteira, 2017.

TÁpia, M.; Nóbrega, T.M (Org.) Haroldo de Campos - transcriação. São Paulo: Perspectiva, 2013.

Wendling, I. et al. "Influência da minieataquia seriada no vigor de minicepas de clones de Eucalyptus grandis”. Rev. Árvore, Viçosa, v. 27, n. 5, Oct. 2003. Disponível em: https://www.scielo.br/scielo.php?script=sci_arttext\&pid=So10o67622003000500003. Acesso 21 de março 2020.

Recebido em 31 de março de 2021.

Aprovado em 15 de junho de 2021.

\section{Resumo}

Transfusões linguísticas: o percurso plagiotrópico na transcriação das duas cenas finais de Fausto II, por Haroldo de Campos

\section{Ana Carolina Costa}

Este artigo tem por objetivo realizar uma leitura, guiada pelo princípio plagiotrópico, da tradução das duas cenas finais do Fausto II, de Goethe, efetuada por Haroldo de Campos. O termo plagiotropia, oriundo do campo biológico, foi aproveitado pelo crítico, tradutor e poeta paulista para explicar o desenvolvimento da tradição literária, lançando sobre essa uma noção de plasticidade: a força motriz que permite o desenvolvimento e a conjugação das poéticas ao longo do tempo é também transversal (Campos, 2005). Aqui, do mesmo modo, o estudo dessa união de poéticas passa necessariamente pelo conceito haroldiano de transcriação: a tradução como criação e como crítica. Nesta esteira, focalizando a intertextualidade de Goethe, que se utiliza do tom dos coveiros hamletianos na cena "Enterramento", Campos, pautado pela noção de tradução como crítica, transcriará a cena através do diálogo com João Cabral de Melo Neto. O coro dos lêmures, em português, está imbricado pelos versos de Morte e vida severina intensificando, assim, o processo de ramificação oblíqua. Para efeito de compressão desse gesto tradutório, refletiremos sobre o que chamamos de diç̧ão da pá, a concretude cabralina, objetivando compreender como Haroldo de Campos o aproveita em sua tradução. Em sua prática transluciferina, Campos adota a fissura da forma e do conteúdo para usurpar, pelas frestas do discurso, o trono do texto original.

Palavras-chave: Haroldo de Campos, tradução, Goethe, plagiotropia. 